\title{
Article \\ Plant-Based Nutritional Supplementation Attenuates LPS-Induced Low-Grade Systemic Activation
}

\author{
Jin Yu ${ }^{1}$, Hong Zhu ${ }^{1}$, Saeid Taheri ${ }^{1}$, William Mondy ${ }^{1}$, Stephen Perry ${ }^{2}$ and Mark S. Kindy ${ }^{1,3,4,5, *}$ \\ 1 Department of Pharmaceutical Sciences, College of Pharmacy, University of South Florida, \\ Tampa, FL 33612, USA; jinyu@usf.edu (J.Y.); hongzhu@usf.edu (H.Z.); taheris@usf.edu (S.T.); \\ wmondy@usf.edu (W.M.) \\ 2 NutriFusion ${ }^{\circledR}$ LLC, Naples, FL 34109, USA; sperry@consealint.com \\ 3 Department of Neurology, College of Medicine, University of South Florida, Tampa, FL 33620, USA \\ 4 James A. Haley VA Medical Center, Tampa, FL 33612, USA \\ 5 Shriners Hospital for Children, Tampa, FL 33612, USA \\ * Correspondence: kindym@usf.edu
}

Citation: Yu, J.; Zhu, H.; Taheri, S.; Mondy, W.; Perry, S.; Kindy, M.S.

Plant-Based Nutritional

Supplementation Attenuates LPS-Induced Low-Grade Systemic Activation. Int. J. Mol. Sci. 2021, 22, 573. https://doi.org/10.3390/ ijms22020573

Received: 2 November 2020

Accepted: 4 January 2021

Published: 8 January 2021

Publisher's Note: MDPI stays neutral with regard to jurisdictional clai$\mathrm{ms}$ in published maps and institutional affiliations.

Copyright: $(2021$ by the authors. Licensee MDPI, Basel, Switzerland. This article is an open access article distributed under the terms and conditions of the Creative Commons Attribution (CC BY) license (https:// creativecommons.org/licenses/by/ $4.0 /)$.

\begin{abstract}
Plant-based nutritional supplementation has been shown to attenuate and reduce mortality in the processes of both acute and chronic disorders, including diabetes, obesity, cardiovascular disease, cancer, inflammatory diseases, and neurological and neurodegenerative disorders. Lowlevel systemic inflammation is an important contributor to these afflictions and diets enriched in phytochemicals can slow the progression. The goal of this study was to determine the impact of lipopolysaccharide (LPS)-induced inflammation on changes in glucose and insulin tolerance, performance enhancement, levels of urinary neopterin and concentrations of neurotransmitters in the striatum in mouse models. Both acute and chronic injections of LPS ( $2 \mathrm{mg} / \mathrm{kg}$ or $0.33 \mathrm{mg} / \mathrm{kg} /$ day, respectively) reduced glucose and insulin tolerance and elevated neopterin levels, which are indicative of systemic inflammatory responses. In addition, there were significant decreases in striatal neurotransmitter levels (dopamine and DOPAC), while serotonin (5-HT) levels were essentially unchanged. LPS resulted in impaired execution in the incremental loading test, which was reversed in mice on a supplemental plant-based diet, improving their immune function and maintaining skeletal muscle mitochondrial activity. In conclusion, plant-based nutritional supplementation attenuated the metabolic changes elicited by LPS injections, causing systemic inflammatory activity that contributed to both systemic and neurological alterations.
\end{abstract}

Keywords: diet; LPS; inflammation; metabolism; immune system

\section{Introduction}

Poor eating habits and diets enriched in high cholesterol or fats have become a major health issue and represent a significant cause of disability and mortality in the United States and around the world [1-3]. An unhealthy diet is a major risk factor for a number of chronic diseases, including diabetes, obesity, cardiovascular disease, cancer and even links to neurological and neurodegenerative diseases where alterations in the diet can have a profound effect on outcomes $[4,5]$.

Various model systems have been examined to determine the impact of diets on chronic disorders and the potential links to human outcomes [6-8]. Studies in animal models have demonstrated that diets enriched in flavonoids, phytochemicals, carotenoids, etc., can alter the processes of diseases and may provide certain links to human disorders as clinical implications [9]. Therefore, diets are one lifestyle aspect that can have an impact on both our physical and mental well-being, contributing to reductions in diabetes, obesity, cardiovascular and cerebrovascular diseases, as well as many other disorders [10-12].

Low-level chronic inflammation is seen in many different disease states [13-15]. Inflammation is an essential component of innate immunity [16]. Inflammation is a response 
to cellular injury and is evident by increased blood flow, capillary dilatation, leucocyte infiltration, and the production of a host of chemical mediators, which serve to instigate the purging of toxic mediators and the repair of damaged tissue $[17,18]$. Attenuation or reduction in inflammation is a process involving cytokines and other anti-inflammatory factors, and is a more intricate process than the switching off of pro-inflammatory markers $[19,20]$. Neopterin is an important biomarker of immune system activation and is beneficial in the analysis of anti-inflammatory properties of nutrition [21]. Neopterin, which is derived from tetrahydrobiopterin (BH4) is generated in macrophages and microglia when stimulated by cytokines. A number of neurodegenerative diseases are also associated with inflammation. Neuroinflammation involves the triggering of glial cell activation and the release of inflammatory cytokines such as tumor necrosis factor- $\alpha$ (TNF- $\alpha$ ), as well as interleukins-1 $\beta$ (IL-1 $\beta$ ) and IL-6 [22-24]. These cytokines function in various ways to promote neuronal cell death in disorders like Parkinson's disease (PD) or Alzheimer's disease $(\mathrm{AD})$, and in so doing contribute to pathologenesis $[25,26]$. We and others have shown that, in a number of neurodegenerative diseases, in addition to neuroinflammation, there is a systemic component that exacerbates these diseases and promotes the progression to neurodegeneration [27].

GrandFusion ${ }^{\circledR}(\mathrm{GF})$ supplements are blends of fruits and vegetables that contain significant levels of vitamins and phytonutrients that can limit the impact of aging, cerebral ischemic injury, and traumatic brain injury by altering inflammatory markers and reactive oxygen species (ROS) [28]. In addition, we have shown that GF blends can improve physical activity mediated by antioxidant enzymes and signaling pathways $[29,30]$. Our previous studies have demonstrated that these diets have a multitude of anti-inflammatory, antioxidant, neuroprotective and neurogenic properties $[29,30]$.

In the current study, our goal was to determine the influence of diets rich in vegetables and fruits on the outcomes associated with acute and chronic low-grade systemic inflammation in a mouse model using LPS as a trigger. Mice were fed diets enriched in fruits and vegetables for 2 months prior to the study and then subjected to lipopolysaccharide (LPS) injections to induce inflammation. The objective of the study was to determine if the presence of these nutraceutical and phytochemicals can limit the extent of the injury following LPS. The results demonstrated that these diets were able to limit the extent of injury triggered by LPS/inflammation. Glucose and insulin tolerance, body weight, workload, neopterin levels, systemic and neurological assessments were altered in the LPS-treated animals, but these alterations were corrected in the diet supplemented animals. These data suggest that these diets can impact the changes seen in low-level chronic inflammation in order to improve outcomes.

\section{Materials and Methods}

\subsection{Animals Male}

C57BL/ 6 mice (10-12 weeks, 25-30 g) from Jackson Laboratory (Bar Harbor, ME, USA) were maintained in a controlled environment $\left(23^{\circ} \mathrm{C} \pm 1.5^{\circ} \mathrm{C}, 12\right.$-h light/dark cycle) with water and food ad libitum. All studies were approved by the Institutional Animal Care and Use Committee at the University of South Florida and the Veterans Affairs Medical Center. This study adhered to the Guidelines for the Care and Use of Laboratory Animals developed by the Office of Laboratory Animal Welfare. All efforts were made to minimize the number of animals used and their suffering. Ten mice were included per experimental group, unless otherwise stated.

\subsection{Nutritional Supplementation}

Animals were fed a normal diet or a normal diet with $\sim 2 \%$ supplementation of NutriFusion (NF)-216 (GrandFusion-Fruit and Veggie \#1 Blend, Table 1) for 2 months [26-29]. Animals were gavaged with the supplements on a daily basis, once per day. GrandFusion supplements were prepared by NutriFusion, LLC (www.nutrifusion.com). Average food 
intake was $3.68 \pm 0.09 \mathrm{~g} /$ day $/$ mouse, and the average consumption of the diets was $0.09 \pm 0.006 \mathrm{~g} /$ day $/$ mouse.

Table 1. Composition of GrandFusion Supplement.

\begin{tabular}{ccc}
\hline t6 Essential Vitamins & $\mathbf{\% ~ d v}$ & Maximum Premix Claim Per 225.00 $\mathbf{~ m g}$ \\
\hline Vitamin A & 50.00 & $2500.00 \mathrm{IU}$ \\
Vitamin C & 50.00 & $30.00 \mathrm{mg}$ \\
Vitamin D & 50.00 & $200.00 \mathrm{IU}$ \\
Vitamin E & 50.00 & $15.00 \mathrm{IU}$ \\
Vitamin B1 & 50.00 & $0.7500 \mathrm{mg}$ \\
Vitamin B6 & 50.00 & $1.00 \mathrm{mg}$ \\
\hline
\end{tabular}

Blend \#1: Fruit and Vegetable Blend (NF-216), Vegetable: Powdered Tomato, Broccoli, Carrot, Shitake Mushroom, Fruit: Powdered Cranberry, Apple, Orange, Made from 100\% organic materials.

\subsection{Incremental Loading Test}

The incremental loading test was initiated at $10 \mathrm{~m} / \mathrm{min}$, and increased $2 \mathrm{~m} / \mathrm{min}$ every $3 \mathrm{~min}$, using a treadmill grade of $9 \%$, until the mice were tired. Exercise was accomplished using a horizontal treadmill with individual lanes. Animals were allowed to run on their own without stimulation. The time to fatigue $(\mathrm{min})$ and the determined exercise workload $(\mathrm{N} \cdot \mathrm{m})$ were assessed as indexes of exercise performance. Exercise workload was calculated using the following parameters: (body mass, in $\mathrm{kg}) \times\left(9.81 \mathrm{~m} / \mathrm{s}^{2}\right) \times($ treadmill speed, $\mathrm{m} / \mathrm{s})$ $\times($ time of exercise, $\mathrm{min}) \times($ treadmill inclination, $\%)$ [31].

\subsection{Injections and Chronic Infusions of LPS}

Mice were injected intraperitoneally (i.p.) with Escherichia coli (E. coli) LPS (lot 3129; serotype 0127:B8; Sigma) $0.33 \mathrm{mg} / \mathrm{kg}$ in a volume of $10.0 \mathrm{~mL} / \mathrm{kg}$ or saline $(0.9 \% \mathrm{NaCl})$ [32]. The treatment elicited greater levels of IL-1 $\beta$ in the brain of LPS-injected mice (up to 100fold; data not shown) $4 \mathrm{~h}$ after administration. A second group of mice had mini-osmotic pumps (Alzet ${ }^{\circledR}$ Model 2002; Alza, Palo Alto, CA, USA) implanted subcutaneously between the scapulae, connected to the peritoneal cavity by a catheter, for continuous i.p. LPS infusion ( 0.33 or $0.83 \mathrm{mg} / \mathrm{kg} /$ day in a flow of $0.5 \mu \mathrm{L} / \mathrm{h}$ for 2 weeks). For mini-osmotic pump implantation, mice were anesthetized with ketamine $(80 \mathrm{mg} / \mathrm{kg})$ and xylazine $(20 \mathrm{mg} / \mathrm{kg})$ i.p. The pumps were filled with saline or LPS [33].

\subsection{Glucose Tolerance Test}

After overnight fasting, mice were fed with glucose ( $2 \mathrm{~g} / \mathrm{kg}$; p.o.). Blood was drawn (tail vein) at $0,15,30,60,90$ and $120 \mathrm{~min}$ following the glucose load. Glucose concentrations were measured using a glucose meter (Optium ${ }^{\mathrm{TM}}$ Xceed, Abbott, Alameda, CA, USA). The oral glucose tolerance tests (OGTT) were executed either $6 \mathrm{~h}$ after the acute intraperitoneal injection of LPS or at the end of the sustained LPS intraperitoneal administration. Control mice were administered with saline.

\subsection{Insulin Tolerance Test}

Mice were fasted $(6 \mathrm{~h})$ and then challenged with insulin $(0.5 \mathrm{U} / \mathrm{kg}$ Humalog, i.p.) and blood glucose levels were measured for the insulin tolerance test (ITT). Different groups of animals $(n=10)$ were used for the analysis of OGTT and ITT.

\subsection{Neopterin Measurement by HPLC}

Neopterin levels were assayed in the urine by high-performance liquid chromatography (HPLC). Urine samples were collected following these two criteria: (i) collect urine without any direct intervention to avoid stress; or (ii) obtain pure urine without contamination with feces or animal feed. The changes in urinary neopterin levels depend on the degree of peripheral immune system activation, which is also directly connected to the intensity of exercise, duration and training status. Samples of urine were collected at 0 and 
$1,3,7,10$ and 14 days after initiation of the study. Samples were collected by the single animal method described previously. Briefly, an individual mouse urinates on plastic wrap, outside of the cage [34]. The urine is then collected into a microcentrifuge tube, quickly spun down and frozen at $-80^{\circ} \mathrm{C}$. When all samples are collected, they are centrifuged at $16,000 \times g$ for $10 \mathrm{~min}$ at $4{ }^{\circ} \mathrm{C}$ and diluted in 10 volumes $(v / v)$ of $15 \mathrm{mM}$ potassium phosphate buffer, containing $5 \mathrm{mM}$ EDTA. The HPLC analysis of urinary neopterin was determined using a Supercosil LC-18-T $5 \mu \mathrm{m}$ reverse-phase column $(15 \times 4.6 \mathrm{~mm})$, using a flow rate of $0.7 \mathrm{~mL} / \mathrm{min}$ with an elution of $85 \% 15 \mathrm{mM}$ potassium phosphate buffer, containing $15 \%$ acetonitrile, $\mathrm{pH} 6.4$. The column temperature was maintained at $35^{\circ} \mathrm{C}$. The neopterin was identified and quantified by a multi-wavelength fluorescence detector (module 2475, Waters, Milford, MA, USA) with an excitation wavelength of $355 \mathrm{~nm}$ and an emission wavelength of $438 \mathrm{~nm}$ [35]. The results were expressed as $\mu \mathrm{mol}$ (neopterin)/mol creatinine. Creatinine levels were analyzed using a colorimetric kit (ThermoFisher, Waltham, MA, USA).

\subsection{Dopamine, DOPAC and 5-HT Measurement by HPLC}

Dopamine (DA), 3,4-dihydroxyphenyilacetic acid (DOPAC) and serotonin (5-HT) were analyzed in the striatum by high-performance liquid chromatography (HPLC, Alliance e2695, Waters, Milford, USA) with electrochemical detection (Waters 2465, Waters, Milford, MA, USA) at a voltage of $+400 \mathrm{mV}$. Striatal samples were isolated at the end of the vehicle infusions or after sustained LPS for 2 weeks. From each group, five mice were euthanized by decapitation into liquid nitrogen. Brains were removed and the striatum was isolated and stored at $-80{ }^{\circ} \mathrm{C}$. The striatum was sonicated and centrifuged $(16,000 \times g$ for $10 \mathrm{~min}$ at $4{ }^{\circ} \mathrm{C}$ ) in cold $0.1 \mathrm{M}$ perchloric acid. Monoamines and metabolites in the supernatants were analyzed by HPLC, as described above. The temperature of the column was maintained at $30^{\circ} \mathrm{C}$. Twenty microliters of supernatant was assessed on a $150 \times 2.0 \mathrm{~mm}, 4 \mu \mathrm{m}, \mathrm{C} 18$ column (Synergi Hydro, Thunder Bay, ON, Canada) with $90 \mathrm{mM}$ sodium phosphate, $50 \mathrm{mM}$ citric acid, $1.7 \mathrm{mM}$ sodium 1- heptane-sulfonate, $50 \mu \mathrm{M}$ ethylenediaminetetraacetic acid, $10 \%$ acetonitrile, $\mathrm{pH} 3.0$, with a flow of $0.25 \mathrm{~mL} / \mathrm{min}$ as the mobile phase [35]. DA, DOPAC and $5-\mathrm{HT}$ concentrations in the supernatants were determined as $\mathrm{ng} / \mathrm{mg}$ protein.

\subsection{Measurement of Respiratory Chain Complex I Activity}

At the termination of the sustained LPS or vehicle infusions for 2 weeks, the quadriceps muscles were isolated, assembled and homogenized in 10 volumes $(v / v)$ of $4.4 \mathrm{mM}$ potassium phosphate buffer (PBS), pH 7.4, containing $0.3 \mathrm{M}$ sucrose, $5 \mathrm{mM}$ MOPS, $1 \mathrm{mM}$ EGTA and $0.1 \%$ BSA. The homogenized samples were centrifuged at $3000 \times g$ for $10 \mathrm{~min}$ at $4{ }^{\circ} \mathrm{C}$. The supernatant was isolated and frozen and thawed for three cycles to allow for the rupture of the mitochondrial membranes. The rate of NADH-dependent ferricyanide reduction at $420 \mathrm{~nm}\left(30^{\circ} \mathrm{C}, \varepsilon=1 \mathrm{mM}^{-1} \times \mathrm{cm}^{-1}\right)$ was used to determine the Complex I activity [36].

\subsection{Protein Determination}

Protein levels were measured by the Lowry method, using bovine serum albumin and 96-well plates.

\subsection{Statistical Analysis}

The data are presented as the mean \pm SEM (standard error of mean). We analyzed the data using one-way or two-way analyses of variance (ANOVA) and post-hoc Bonferroni or Tukey's tests, where F was significant. We used the Student's $t$-test for independent samples when comparing two independent groups. The exercise incremental load test data were depicted as the percentage of animals that successfully completed the task at given speeds. In this case, group differences were examined by applying log-rank (Mantel-Cox). Significance for the tests was considered at $p<0.05$. Statistics and all graphs were analyzed using GraphPad Prism $7^{\circledR}$. 


\section{Results}

\subsection{Continuous LPS Injections Reduced Glucose Tolerance}

Figure 1 illustrates the blood glucose and insulin levels after a single injection of LPS. LPS elevated the glucose clearance and reduced the area under the curve (AUC), suggesting a greater nutrient requirement during the time of acute inflammation when compared to the control group (Figure 1A,B). When the animals were provided with a diet enriched in fruits and vegetables, and then subjected to LPS treatment, the glucose tolerance showed a return almost to control levels. For analysis of the insulin tolerance, $6 \mathrm{~h}$ after a single injection of LPS ( $2 \mathrm{mg} / \mathrm{kg}$ or $0.33 \mathrm{mg} / \mathrm{kg}$ ), mice were injected with insulin and the glycemia index was determined. Acute injection of LPS elevated insulin sensitivity (Figure 1C,D). Again, when the animals were provided a diet enriched in fruits and vegetables, and then subjected to LPS treatment, the insulin tolerance showed a return almost to control levels.

A.

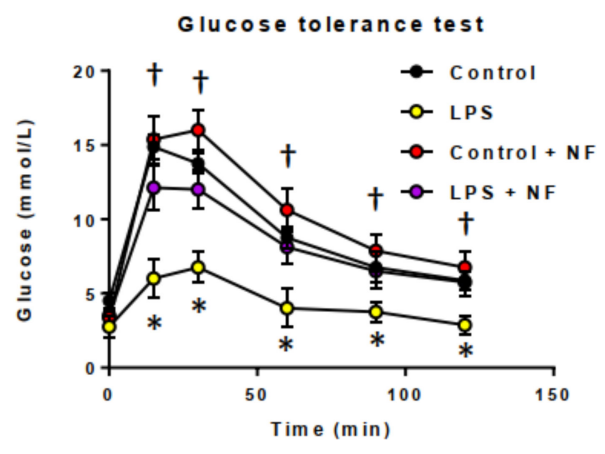

C.

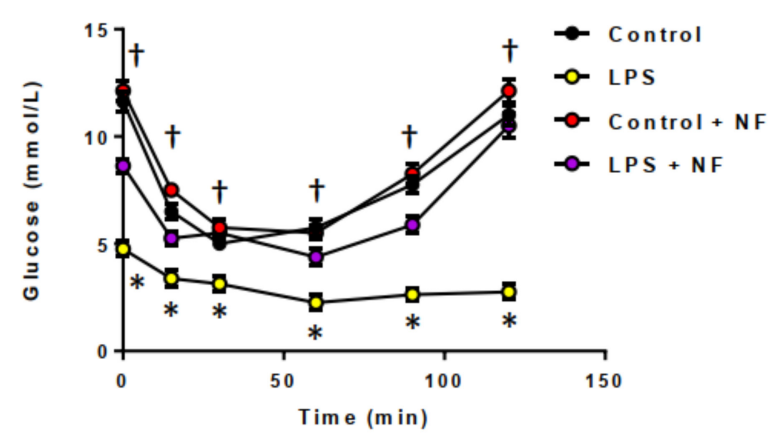

B.

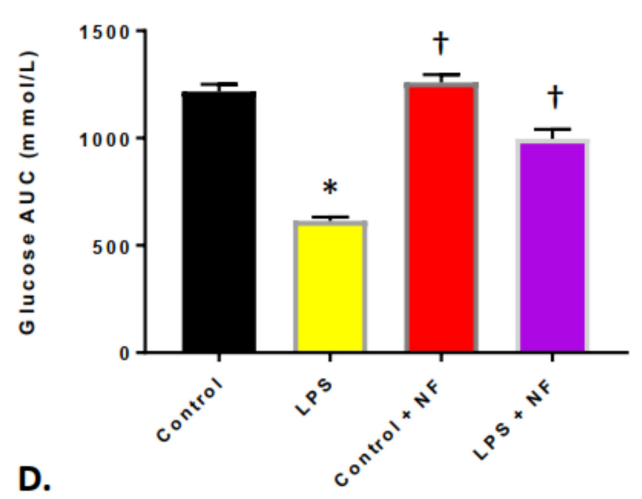

D.

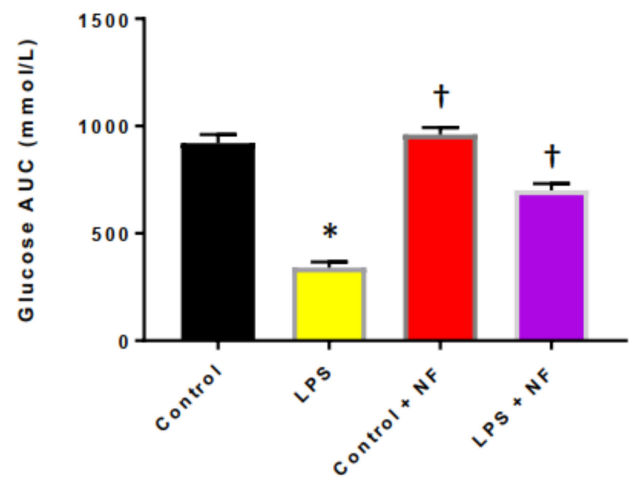

Figure 1. Effect of acute lipopolysaccharide (LPS) administration on glucose and insulin tolerance. (A) Oral glucose tolerance test (OGTT, $2 \mathrm{~g} / \mathrm{kg}$, p.o.) performed $6 \mathrm{~h}$ after acute intraperitoneal injection of control (saline, $n=10 / \mathrm{group}$ ), LPS

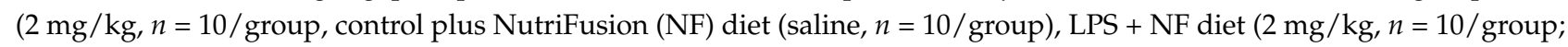
repeated measures one-way ANOVA followed by Bonferroni's test $(\mathrm{d}=1.14)$. (B) AUC of glucose response; Student's t-test. (C) Insulin tolerance test (ITT, $0.5 \mathrm{U} / \mathrm{kg}$, i.p.) performed $6 \mathrm{~h}$ after injection of control (saline, $n=10), \mathrm{LPS}(2 \mathrm{mg} / \mathrm{kg}$, $n=10$ /group), control plus NF diet (saline, $n=10 /$ group), LPS + NF diet ( $2 \mathrm{mg} / \mathrm{kg}, n=10 /$ group; repeated measures one-way ANOVA followed by Bonferroni's test $(\eta 2=0.108)$. (D) AUC of insulin response; one-way ANOVA followed by Bonferroni's test. Values are mean \pm SEM. ${ }^{*} p<0.01$ compared to control group, $\uparrow p<0.01$ compared to LPS group.

Next, we assessed the effect of repeated intraperitoneal LPS administration $(0.33 \mathrm{mg} / \mathrm{kg} /$ day; 2 weeks) on glucose tolerance (Figure 2B). In contrast to acute administration (Figure 1A), the sustained injections of LPS decreased glucose tolerance, as shown in Figure 2A. No difference was found in food intake between the groups (Figure 2A). When the animals were provided a diet enriched in fruits and vegetables, and then subjected to chronic LPS treatment, the glucose tolerance showed a return almost to control levels. 
A.

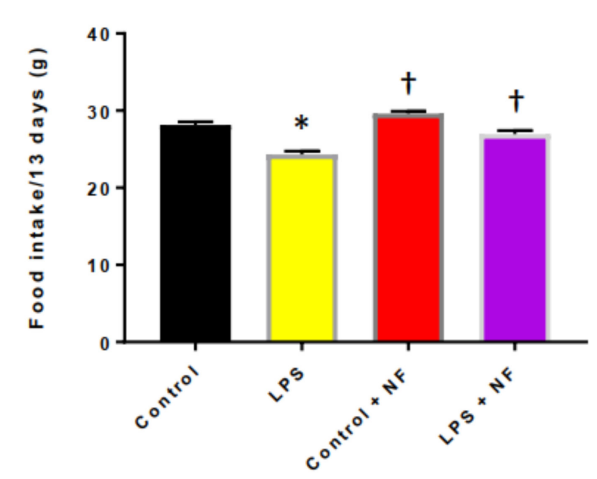

B.

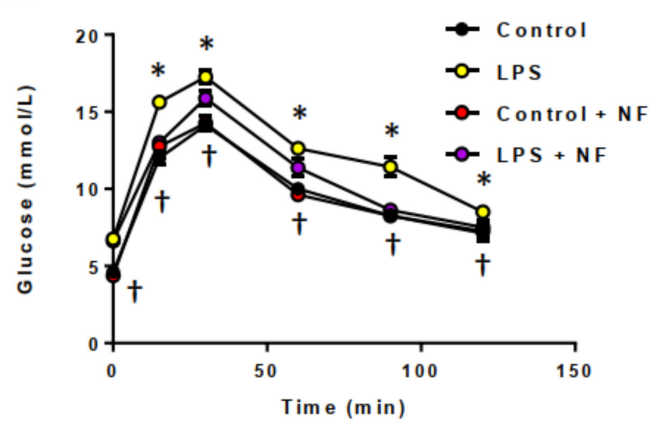

c.

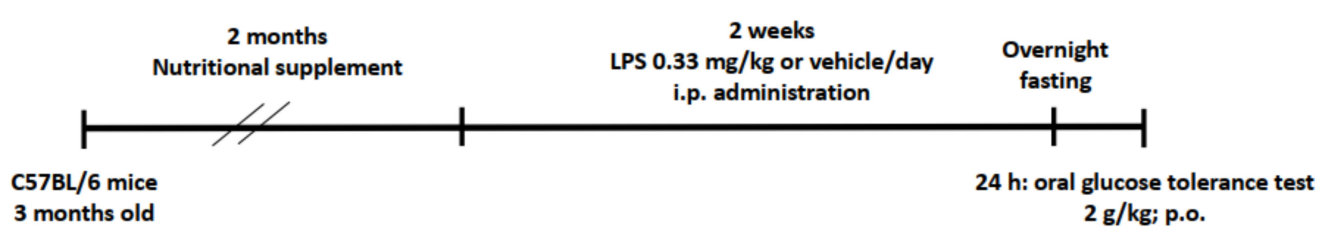

Figure 2. Effect of chronic lipopolysaccharide (LPS) administration on food intake and glucose tolerance. (A) Food intake during 13 days with repeated daily injection of control (saline, $n=10)$, LPS ( $0.33 \mathrm{mg} / \mathrm{kg} /$ day, i.p., $n=10 /$ group), control plus NF diet (saline, $n=10 /$ group), LPS + NF diet; Student's $t$-test. (B) OGTT performed at the end of the repeated daily injection of control (saline, $n=10$ /group), LPS (0.33 mg/kg, i.p., $n=10 /$ group), control plus NF diet (saline, $n=10 /$ group), LPS + NF diet; repeated measures one-way ANOVA followed by Bonferroni's test $(d=-0.62)$. (C) Diagram of experimental design; Student's $t$-test. * $p<0.01$ compared to control group, $+p<0.01$ compared to LPS group.

\subsection{Acute and Sustained Infusion of LPS over a Two-Week Period on Exercise Activity in Mice}

The impact of acute LPS treatment and inflammation on exercise and neopterin levels in mice was determined (Figure 3). As shown in Figure 3A, in the incremental loading test (initiated $24 \mathrm{~h}$ after LPS, $0.33 \mathrm{mg} / \mathrm{kg}$, i.p.), exercise performance was reduced, as seen in both the horizontal and vertical exercise workloads (Figure 3B). LPS treatment resulted in a significant impairment in the early phases of the incremental loading test, after the challenge. Pre-treatment of the mice with the nutritional diets prevented a reduction in workload, maintaining them at control levels. Continuous infusion with LPS $(0.33 \mathrm{mg} / \mathrm{kg} /$ day, i.p.; Figure $3 \mathrm{C})$ decreased the body weight of the mice, specifically in the first two days of the test. Figure 3D illustrates that continuous LPS-mediated inflammatory conditions elevated the neopterin levels in the urine for three days after initiating the LPS infusion. The levels returned to baseline on the seventh day of the test. Finally, the nutritional diet maintained the urinary neopterin at control levels.

\subsection{Continuous Infusion of LPS over a Two-Week Period Provoked Inflammation and Altered Dopamine Metabolism}

In mice treated with a continuous infusion of LPS, the DA levels (Figure 4A) and levels of the metabolic breakdown product, DOPAC (Figure 4B), were significantly decreased in the striatum. The exposure of the mice to the NutriFusion diet reverted the DA and DOPAC to pretreatment levels. No significant difference was detected in the 5-HT levels (Figure 4C); nevertheless, the striatal 5-HT/DA ratio was statistically elevated by LPS (Figure 4D). 
A.

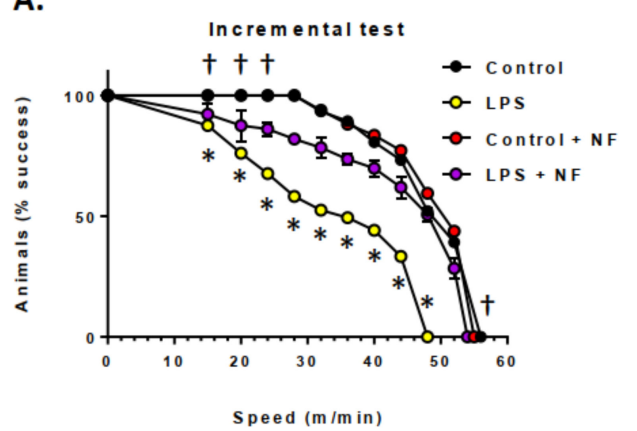

C.

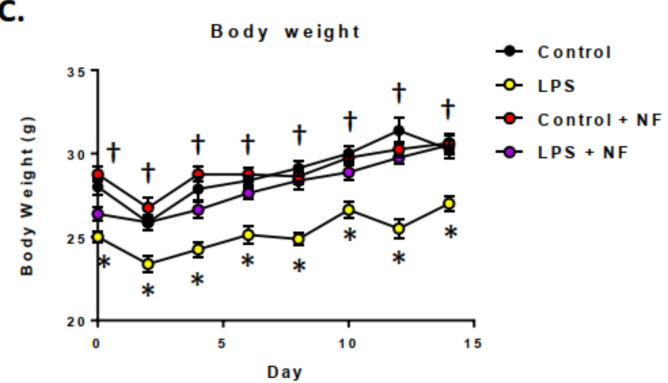

B.

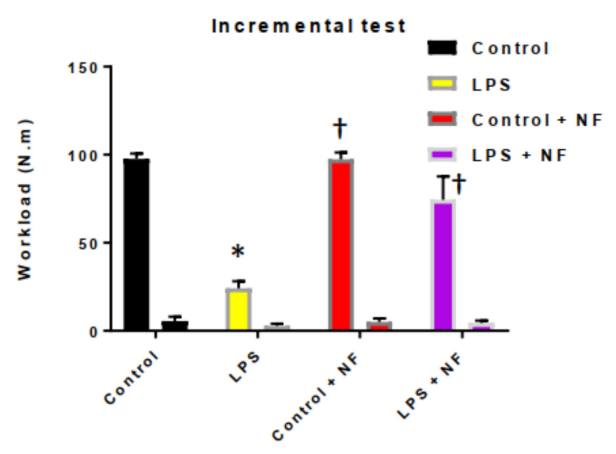

D.

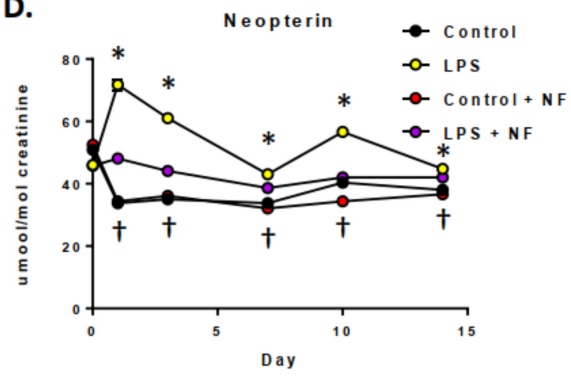

Figure 3. Effect of bacterial lipopolysaccharide (LPS) administration on exercise performance, and urinary neopterin levels in the striatum. (A) Mouse physical performance on treadmill incremental loading test ( $n=10 /$ group); log-rank (Mantel-Cox). The animals were adapted to the treadmill for 5 consecutive days at a speed of $10 \mathrm{~m} / \mathrm{min}$ for $10 \mathrm{~min}$. The incremental loading test was performed $24 \mathrm{~h}$ after a single dose of control (saline), LPS injection $(0.33 \mathrm{mg} / \mathrm{kg}$, i.p.), control plus NF diet (saline), LPS + NF diet ( $n=10$ /group). (B) Vertical (lower bars) and horizontal (higher bars) workloads during incremental loading test; one-way ANOVA followed by the Bonferroni test. (C) Body weight and (D) urinary neopterin production $(n=10$ /group); repeated measures one-way ANOVA followed by Bonferroni's test. Values are mean \pm SEM. ${ }^{*} p<0.01$ compared to control group, $+p<0.01$ compared to LPS group.

A.

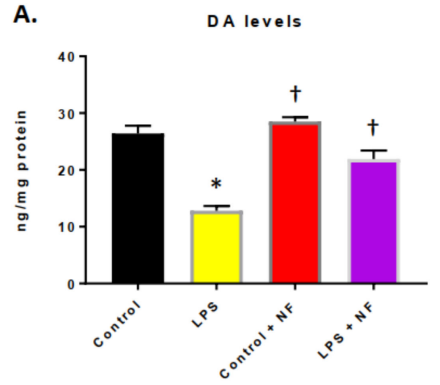

c.

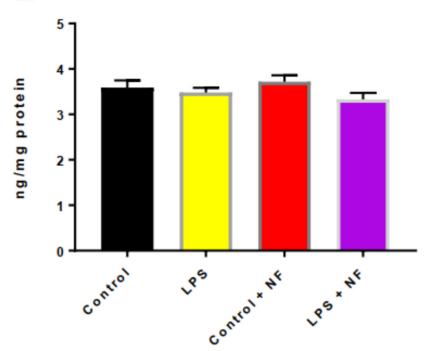

B.

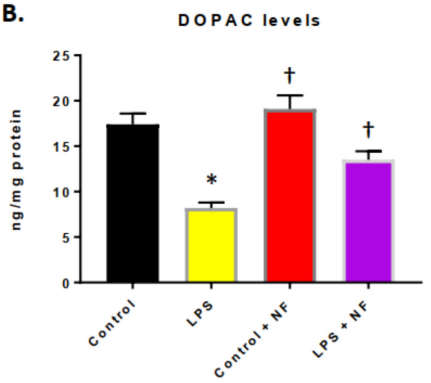

D.

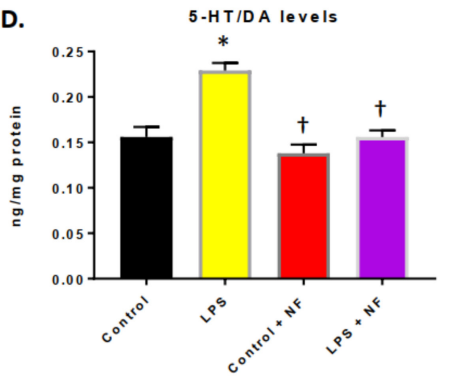

Figure 4. Effect of bacterial lipopolysaccharide (LPS) administration on monoamine levels in the striatum. (A) Dopamine (DA), (B) 3,4-dihydroxyphenyilacetic acid (DOPAC), (C) serotonin (5-HT) levels and (D) 5-HT/DA ratio in control (saline), LPS injection $(0.33 \mathrm{mg} / \mathrm{kg}$, i.p.), control plus NF diet (saline), LPS + NF diet ( $n=10$ /group); Student's $t$-test. Values are mean \pm SEM. ${ }^{*} p<0.01$ compared to control group, $\uparrow p<0.01$ compared to LPS group. 


\subsection{Nutritional Diet Mitigated the Exacerbation of Immune System Initiation and Maintained Mitochondrial Activity}

The impact of the NutriFusion diets on the production of neopterin and mitochondrial complex I activity in skeletal muscle were determined in mice infused with LPS and provided with daily nutritional diets. Mice were provided with these diets for 2 months and then treated with LPS ( $0.83 \mathrm{mg} / \mathrm{kg} /$ day, i.p.; mini-osmotic pumps for 2 weeks; Figure 5A). Figure 5A illustrates the elevated neopterin levels in the urine in the LPS treated group, which were attenuated by nutritional prophylaxis. Additionally, the NutriFusion diet temperately elevated the neopterin levels (compared to the non-inflammatory conditions). Moreover, the addition of the diet mitigated the decrease in mitochondrial complex I activity seen in the skeletal muscle of mice exposed to LPS (Figure 5B).
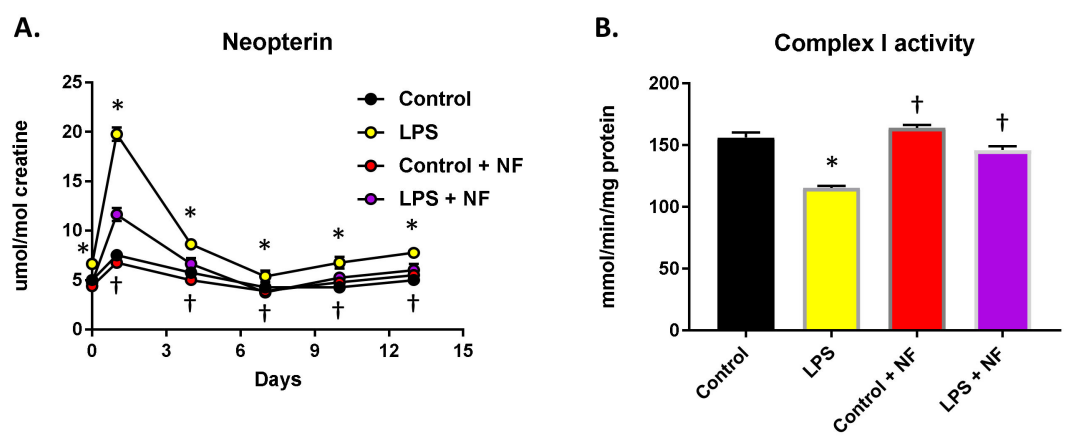

Figure 5. Effect of nutritional diets on inflammatory response (animals submitted to nutritional diets for 2 months). Afterwards, mini-osmotic pumps containing LPS $0.83 \mathrm{mg} / \mathrm{kg} /$ day were implanted and LPS was infused for 2 weeks. (A) Neopterin urinary levels; repeated measures two-way ANOVA followed by Bonferroni's test. Groups were: control (saline), LPS injection $(0.33 \mathrm{mg} / \mathrm{kg}$, i.p.), control plus NF diet (saline), and LPS + NF diet. (B) Complex I activity in skeletal muscle ( $n=10 /$ group); two-way ANOVA followed by Tukey's test. Values are mean \pm SEM. ${ }^{*} p<0.01$ compared to control group, $\uparrow p<0.01$ compared to LPS group.

\section{Discussion}

In the present study, we examined the influence of a diet enriched with vegetables and fruits on the alterations in acute and chronic inflammation. We found that that consumption of this particular diet for at least a 2-month period helped to reduce the outcomes of both acute and chronic inflammation induced by LPS.

Acute inflammation can play a protective role by responding to cellular stress signals that result from immune cell activation and the injured tissue $[37,38]$. Low-level chronic inflammation is typified by the elevation of specific proinflammatory mediators that are associated with many chronic disorders and are important in the pathogenesis of diabetes and obesity, as well as other systemic disorders and even neurological diseases [39]. Therefore, decreasing inflammation in the body is a pathway to not only the attenuation of disease progression, but also its possible prevention. Diets enriched in phytochemicals (which are found in fruits and vegetables) are not regularly consumed because of access, cost and the fact that their quality can give rise to systemic inflammation [39]. The food pyramid, which indicates that people need to consume 2-4 servings of fruits and 3-5 servings of vegetables per day, is difficult if not impossible because of many complications. In addition, reductions in red meat, fats, oils and sweets are recommended but the majority of people in the US do not follow these guidelines. A simple, more productive approach is needed to provide the nutrition and health benefits of phytochemicals, anti-inflammatory and antioxidant complexes.

We showed in this study that chronic inflammation compromised both glucose and insulin tolerance, which is normally seen in certain chronic metabolic diseases. In addition, the administration of LPS resulted in an increase in neopterin levels, which is a marker for immune system activation. We showed that a diet enriched in fruits and vegetables 
(and consequently phytochemicals) was able to reverse the process and maintain and even elevate insulin sensitivity and glucose tolerance. In an acute inflammatory state, insulin sensitivity and glucose tolerance were increased, possibly due to the inhibition of glucose synthesis in the liver in connection to altered toll-like receptor (TLR) expression in target tissues [40]. LPS-mediated effects are related to an increase in TLR4 levels that triggers the activation of nuclear factor-kB (NF-kB), a transcription factor that activates a cascade of inflammatory mediators [41]. These factors control the transcription of inflammatory mediators, such as IL- $1 \beta$, IL-6, TNF- $\alpha$, TNF- $\beta$, INF- $\alpha$, INF $\beta$, INF- $\gamma$ [42]. Inflammation of adipose tissue is an important regulatory point in the promotion of insulin resistance and obesity [42,43]. The inhibition of the downstream signaling of the insulin receptor is a critical mechanism by which inflammatory signaling leads to insulin resistance $[43,44]$. Inflammation can alter insulin action and give rise to diabetes and obesity by blocking insulin receptor downstream events, impairing insulin receptor substrate 1 (IRS-1) activation and phosphatidylinositol 3-kinase-dependent (PI3K) pathways, therefore compromising insulin signaling [45].

Previous studies have shown that the brain maintains homeostasis by communication with the systemic physiological system [46-48]. The systemic circulation is prevented from entering the brain by the blood brain barrier (BBB) and the local environment. Changes in $\mathrm{pH}$, metabolic disorders, and other factors, such as infections, systemic inflammation, organ dysfunction, can alter the BBB and impact the functioning in the brain [48].

Our data demonstrated that systemic inflammation (generated by LPS) also increased neopterin levels in the urine and resulted in altered neuronal activity by decreasing dopamine (DA) metabolism. Neuroinflammation has been extensively studied over the years and the link to systemic inflammation is beginning to be observed [49,50]. Inflammation is associated with the development and progression of neurological diseases such as Alzheimer's disease (AD), Parkinson's disease (PD), stroke and many other diseases. We and others have suggested that systemic chronic metabolic diseases, in turn, compromise the blood-brain barrier (BBB) and bear changes in the brain that impart a sensitivity and susceptibility to neurological and neurodegenerative changes [51]. Elevated levels of inflammatory mediators in the brain can alter neurogenesis, synaptic formation and neuronal sprouting, resulting in a decrease in cognitive ability. Studies have shown that increased inflammation can result in altered DA signaling and maintenance of dopaminergic neurons.

Inputs into the basal ganglia via the striatum are necessary for the control of voluntary movement and neurons in the striatum signal the preparatory, initiation and execution of these movements [52,53]. Diseases like Parkinson's disease (PD), occur from the loss of dopamine producing neurons which results in movement disorders leading to difficulties in motor activities. Recent studies have suggested that there is an emerging role for nutrition in PD and this may alter dopamine levels and impact the D2/D3 dopamine receptor binding $[54,55]$. In addition, diet can impact the microbiome to reduce inflammatory aspects that could help limit the extent of PD in individuals [55]. Foods are natural sources of chemicals that may exert critical effects on the nervous system in humans. Some of these chemicals are the neurotransmitters (NTs) acetylcholine (ACh), the modified amino acids glutamate and $\gamma$-aminobutyric acid (GABA), and the biogenic amines dopamine, serotonin (5-HT), and histamine [56]. Of interest is the ability of flavonoids to activate the extracellular signal-regulated kinase and the Akt signaling pathways, leading to the activation of the cyclic adenosine monophosphate (cAMP) response element binding protein, a transcription factor that increases the expression of a number of neurotrophins important in LTP and long-term memory. One such neurotrophin is BDNF, which is known to be crucial in controlling synapse growth, promoting an increase in dendritic spine density, and enhancing synaptic receptor density [57].

The effects of nutrition on immune system function have been studied over the years and have been shown to impact urinary neopterin levels [58]. Neopterin is a by-product of the BH4 de novo pathway and, under inflammatory conditions, the pathways involved in its generation are altered and neopterin accumulates in the blood [59]. Thus, an increase in 
neopterin levels has been recognized a sensitive biomarker for immune system activation. Additionally, studies have shown that dietary supplements were significantly effective in improving the redox status by effectively increasing the reduced-glutathione (GSH) levels and other reduced thiol entities while appreciably decreasing the oxidized species [60]. The beneficial outcome of the redox status was significant in the specific groups which also experienced a significant reduction in neopterin levels. To understand how this work mechanistically, elevated neopterin levels would lead to the activation of a master transcription factor nuclear factor erythroid 2-related factor 2 (Nrf2), which is a key regulator of the cellular antioxidant response. This response will further enhance the cellular antioxidant defenses, mitochondrial activity and the anti-inflammatory environment. Increased Nrf2 expression and increased downstream antioxidant proteins are increased in the brain after neopterin treatment [61-63]. It is suggested that selected diets: (i) prevent the aggravated increase of neopterin in an inflammatory state and (ii) dietary intake can increase the neopterin levels as a mechanism to prevent oxidative stress and inflammation. Our studies show that neopterin is elevated in chronic inflammation and nutritional supplementation can protect against this increase.

Several studies have demonstrated that diets enriched in fruits and vegetables can have anti-inflammatory and dynamic metabolic effects [27-30]. Our earlier studies have revealed that nutritional supplementation assisted in the improvement of outcomes from neurological disorders, diminished changes in age-related deficiencies and enhanced physical consequences [26,27]. We established that diets enriched in phytochemicals limited the injury and improved behavioral outcomes in mice subjected to cerebral ischemic injury [64]. Our experiments denoted that these diets were able to diminish inflammatory mediators and oxidative damage and therefore augment neuronal improvement [27-30]. We were also able to show that dietary supplementation in aged rats validated a reversal of the age-related phenomenon of elevated inflammation and reactive oxygen species (ROS) and enhanced physical activity in older animals [29]. These data insinuate that supplementation with vegetables and fruits and their associated components are necessary and sufficient to provide protection from injury and to stimulate performance in animal models.

\section{Conclusions}

In conclusion, the strengths of this study show that prolonged use of diets augmented with vegetable and/or fruit extracts mitigated systemic inflammatory conditions when used prophylactically. This demonstrates that diets enriched in anti-inflammatory mediators and other compounds are beneficial in mouse models of inflammation and could mitigate the negative influences of immune system initiation. Therefore, this aspect of the body in its adaptability to inflammation may help to alter the process of acute and chronic inflammatory disorders and protect the body from disease. The limitations of the study are that diseases in mice are not identical to man, and the potential use of nutritional supplements is restricted to prophylaxis and not therapeutic.

Author Contributions: J.Y., and M.S.K. provided the study concept and the design. J.Y., H.Z., W.M., S.T. and M.S.K. acquired the data. S.P. and M.S.K. provided the analysis and interpretation of the data. M.S.K. drafted the manuscript. All authors critically reviewed the manuscript for important intellectual content. J.Y. and M.S.K. supervised the study. All authors have read and agreed to the published version of the manuscript.

Funding: This work was partially supported by grants from the National Institutes of Health (R01 ES016774-01, R21AG043718), VA Merit Award (I101RX001450), and an AHA SFRN grant (15SFDRN25710468) to Kindy. Kindy is a Senior Research Career Scientist in the VA.

Institutional Review Board Statement: All studies were submitted and approved by the Institutional Animal Care and Use Committee (IACUC) at the University of South Florida (USF) and the James A. Haley Veterans Affairs Medical Center (VAMC), protocol IS00006453. The approved study adhered 
to the Guide for the Care and Use of Laboratory Animals developed by the Office of Laboratory Animal Welfare (OLAW).

Informed Consent Statement: Not applicable.

Data Availability Statement: The data presented in this study are available on request from the corresponding author. The data are not publicly available due to privacy issues.

Acknowledgments: The authors wish to acknowledge NutriFusion, LLC for providing the GrandFusion ${ }^{\circledR}$ diets for the studies. We thank William Grand for reviewing the manuscript prior to submission. GrandFusion ${ }^{\circledR}$ is a patent pending product of NutriFusion, LLC.

Conflicts of Interest: Stephen Perry is a technical and science consultant for NutriFusion, LLC.

\section{References}

1. Janssen, H.G.; Davies, I.G.; Richardson, L.D.; Stevenson, L. Determinants of takeaway and fast food consumption: A narrative review. Nutr. Res. Rev. 2018, 31, 16-34. [CrossRef] [PubMed]

2. Popkin, B.M.; Gordon-Larsen, P. The nutrition transition: Worldwide obesity dynamics and their determinants. Int. J. Obes. Relat. Metab. Disord. 2004, 28, S2-S9. [CrossRef] [PubMed]

3. Manzel, A.; Muller, D.N.; Hafler, D.A.; Erdman, S.E.; Linker, R.A.; Kleinewietfeld, M. Role of "Western diet" in inflammatory autoimmune diseases. Curr. Allergy Asthma Rep. 2014, 14, 404. [CrossRef] [PubMed]

4. Van Dam, R.M.; Rimm, E.B.; Willett, W.C.; Stampfer, M.J.; Hu, F.B. Dietary patterns and risk for type 2 diabetes mellitus in US men. Ann. Intern. Med. 2002, 136, 201-209. [CrossRef]

5. Hills, R.D., Jr.; Pontefract, B.A.; Mishcon, H.R.; Black, C.A.; Sutton, S.C.; Theberge, C.R. Gut Microbiome: Profound Implications for Diet and Disease. Nutrients 2019, 11, 1613. [CrossRef] [PubMed]

6. Lee, H.J.; Seo, H.I.; Cha, H.Y.; Yang, Y.J.; Kwon, S.H.; Yang, S.J. Diabetes and Alzheimer's Disease: Mechanisms and Nutritional Aspects. Clin. Nutr. Res. 2018, 7, 229-240. [CrossRef]

7. Pandareesh, M.D.; Kandikattu, H.K.; Razack, S.; Amruta, N.; Choudhari, R.; Vikram, A.; Doddapattar, P. Nutrition and Nutraceuticals in Neuroinflammatory and Brain Metabolic Stress: Implications for Neurodegenerative Disorders. CNS Neurol. Disord. Drug Targets 2018, 17, 680-688. [CrossRef]

8. Shal, B.; Ding, W.; Ali, H.; Kim, Y.S.; Khan, S. Anti-neuroinflammatory Potential of Natural Products in Attenuation of Alzheimer's Disease. Front. Pharmacol. 2018, 9, 548. [CrossRef]

9. Yu, J.; Zhu, H.; Taheri, S.; Mondy, W.; Perry, S.; Kindy, M.S. Impact of nutrition on inflammation, tauopathy, and behavioral outcomes from chronic traumatic encephalopathy. J. Neuroinflamm. 2018, 15, 277. [CrossRef]

10. Harding, A.; Gonder, U.; Robinson, S.J.; Crean, S.; Singhrao, S.K. Exploring the Association between Alzheimer's Disease, Oral Health, Microbial Endocrinology and Nutrition. Front. Aging Neurosci. 2017, 9, 398. [CrossRef]

11. Erro, R.; Brigo, F.; Tamburin, S.; Zamboni, M.; Antonini, A.; Tinazzi, M. Nutritional habits, risk, and progression of Parkinson disease. J. Neurol. 2018, 265, 12-23. [CrossRef]

12. D'Cunha, N.M.; McKune, A.J.; Panagiotakos, D.B.; Georgousopoulou, E.N.; Thomas, J.; Mellor, D.D.; Naumovski, N. Evaluation of dietary and lifestyle changes as modifiers of $S 100 \beta$ levels in Alzheimer's disease. Nutr. Neurosci 2019, 22, 1-18. [CrossRef] [PubMed]

13. Lorenzatti, A.J.; Servato, M.L. New evidence on the role of inflammation in CVD risk. Curr. Opin. Cardiol. 2019, 34, 418-423. [CrossRef] [PubMed]

14. Nasonov, E.L.; Popkova, T.V. Atherosclerosis: Perspectives of anti-inflammatory therapy. Ter. Arkh. 2018, 90, 4-12. [PubMed]

15. Serino, A.; Salazar, G. Protective Role of Polyphenols against Vascular Inflammation, Aging and Cardiovascular Disease. Nutrients 2018, 11, 53. [CrossRef]

16. Arrese, M.; Cabrera, D.; Kalergis, A.M.; Feldstein, A.E. Innate Immunity and Inflammation in NAFLD/NASH. Dig. Dis. Sci. 2016, 61, 1294-1303. [CrossRef]

17. Malynn, B.A.; Ma, A. A20: A multifunctional tool for regulating immunity and preventing disease. Cell. Immunol. 2019, 340, 103914. [CrossRef] [PubMed]

18. Liew, P.X.; Kubes, P. The Neutrophil's Role During Health and Disease. Physiol. Rev. 2019, 99, 1223-1248. [CrossRef] [PubMed]

19. Fazio, F.; Ulivieri, M.; Volpi, C.; Gargaro, M.; Fallarino, F. Targeting metabotropic glutamate receptors for the treatment of neuroinflammation. Curr. Opin. Pharmacol. 2018, 38, 16-23. [CrossRef]

20. Spagnuolo, C.; Moccia, S.; Russo, G.L. Anti-inflammatory effects of flavonoids in neurodegenerative disorders. Eur. J. Med. Chem. 2018, 153, 105-115. [CrossRef]

21. Dantas de Lucas, R.; Caputo, F.; Mendes de Souza, K.; Sigwalt, A.R.; Ghisoni, K.; Lock Silveira, P.C.; Remor, A.P.; da Luz Scheffer, D.; Antonacci Guglielmo, L.G.; Latini, A. Increased platelet oxidative metabolism, blood oxidative stress and neopterin levels after ultra-endurance exercise. J. Sports Sci. 2014, 32, 22-30. [CrossRef] [PubMed]

22. McCauley, M.E.; Baloh, R.H. Inflammation in ALS/FTD pathogenesis. Acta Neuropathol. 2019, 137, 715-730. [CrossRef] [PubMed]

23. Lee, Y.; Lee, S.; Chang, S.C.; Lee, J. Significant roles of neuroinflammation in Parkinson's disease: Therapeutic targets for PD prevention. Arch. Pharm. Res. 2019, 42, 416-425. [CrossRef] [PubMed] 
24. Van Eldik, L.J.; Carrillo, M.C.; Cole, P.E.; Feuerbach, D.; Greenberg, B.D.; Hendrix, J.A.; Kennedy, M.; Kozauer, N.; Margolin, R.A.; Molinuevo, J.L.; et al. The roles of inflammation and immune mechanisms in Alzheimer's disease. Alzheimers Dement (N. Y.) 2016, 2, 99-109. [CrossRef] [PubMed]

25. Heneka, M.T.; Golenbock, D.T.; Latz, E. Innate immunity in Alzheimer's disease. Nat. Immunol. 2015, 16, 229-236. [CrossRef] [PubMed]

26. Yu, J.; Zhu, H.; Taheri, S.; Mondy, W.; Kirstein, C.; Swindell, W.; Ko, D.; Kindy, M.S. GM6 Attenuates Alzheimer's Disease Pathology in APP Mice. Mol. Neurobiol. 2019, 56, 6386-6396. [CrossRef]

27. Yu, J.; Zhu, H.; Taheri, S.; Mondy, W.; Perry, S.; Kirstein, C.; Kindy, M.S. Effects of GrandFusion Diet on Cognitive Impairment in Transgenic Mouse Model of Alzheimer's Disease. Nutrients 2020, 13, 117. [CrossRef] [PubMed]

28. Yu, J.; Zhu, H.; Taheri, S.; Monday, W.L.; Perry, S.; Kindy, M.S. Reduced Neuroinflammation and Improved Functional Recovery after Traumatic Brain Injury by Prophylactic Diet Supplementation in Mice. Nutrients 2019, 11, 299. [CrossRef]

29. Yu, J.; Zhu, H.; Taheri, S.; Perry, S.; Kindy, M.S. The Effect of Diet on Improved Endurance in Male C57BL/6 Mice. Nutrients 2018, 10, 1101. [CrossRef]

30. Yu, J.; Zhu, H.; Perry, S.; Taheri, S.; Kindy, M.S. Daily supplementation with GrandFusion ${ }^{\circledR}$ improves memory and learning in aged rats. Aging (Albany NY) 2017, 9, 1041-1054. [CrossRef]

31. Aguiar, A.S.; Duzzioni, M.; Remor, A.P.; Tristão, F.S.M.; Matheus, F.C.; RaismanVozari, R.; Latini, A.; Prediger, R.D. Moderate-intensity physical exercise protects against experimental 6-hydroxydopamine-induced hemiparkinsonism through Nrf2-antioxidant response element pathway. Neurochem. Res. 2016, 41, 64-72. [CrossRef] [PubMed]

32. Ghisoni, K.; Aguiar, A.S.; de Oliveira, P.A.; Matheus, F.C.; Gabach, L.; Perez, M.; Carlini, V.P.; Barbeito, L.; Mongeau, R.; Lanfumey, L.; et al. Neopterin acts as an endogenous cognitive enhancer. Brain Behav. Immun. 2016, 56, 156-164. [CrossRef] [PubMed]

33. Nguyen, A.T.; Mandard, S.; Dray, C.; Deckert, V.; Valet, P.; Besnard, P.; Drucker, D.J.; Lagrost, L.; Grober, J. Lipopolysaccharidesmediated increase in glucose-stimulated insulin secretion: Involvement of the GLP-1 pathway. Diabetes 2014, 63, 471-482. [CrossRef] [PubMed]

34. Kurien, B.T.; Hal Scofield, R. Mouse urine collection using clear plastic wrap. Lab. Anim. 1999, 33, 83-86. [CrossRef] [PubMed]

35. Castro, A.A.; Ghisoni, K.; Latini, A.; Quevedo, J.; Tasca, C.I.C.I.; Prediger, R.D.S. Lithium and valproate prevent olfactory discrimination and short-term memory impairments in the intranasal 1-methyl-4-phenyl-1,2,3,6-tetrahydropyridine (MPTP) rat model of Parkinson's disease. Behav. Brain Res. 2012, 229, 208-215. [CrossRef]

36. Aguiar, A.S.; Stragier, E.; daLuzScheffer, D.; Remor, A.P.; Oliveira, P.A.; Prediger, R.D.; Latini, A.; Raisman-Vozari, R.; Mongeau, R.; Lanfumey, L. Effects of exercise on mitochondrial function, neuroplasticity and anxio-depressive behavior of mice. Neuroscience 2014, 271, 56-63. [CrossRef]

37. De Paula Martins, R.; Lim, C.K.; Ghisoni, K.; Staats, A.; Dallagnol, K.; Solano, A.; Guillemin, G.J.; Silva Aguiar, A., Jr.; Latini, A. Treating depression with exercise: The inflammasome inhibition perspective. J. Syst. Integr. Neurosci. 2016, 3, 100. [CrossRef]

38. Handschin, C.; Spiegelman, B.M. The role of exercise and PGC1alpha in inflammation and chronic disease. Nature 2008, 454, 463-469. [CrossRef]

39. Hotamisligil, G.S. Inflammation and metabolic disorders. Nature 2006, 444, 860-867. [CrossRef]

40. Creely, S.J.; McTernan, P.G.; Kusminski, C.M.; Fisher, M.; Da Silva, N.F.; Khanolkar, M.; Evans, M.; Harte Kumar, S. Lipopolysaccharide activates an innate immune system response in human adipose tissue in obesity and type 2 diabetes. AJP Endocrinol. Metab. 2006, 292, E740-E747. [CrossRef]

41. Dasu, M.R.; Devaraj, S.; Park, S.; Jialal, I. Increased Toll-Like Receptor (TLR) activation AL and TLR ligands in recently diagnosed type2 diabetic subjects. Diabetes Care 2010, 33, 861-868. [CrossRef] [PubMed]

42. Piccinin, E.; Villani, G.; Moschetta, A. Metabolic aspects in NAFLD, NASH and hepatocellular carcinoma: The role of PGC1 coactivators. Nat. Rev. Gastroenterol. Hepatol. 2019, 16, 160-174. [CrossRef] [PubMed]

43. Hallal, P.C.; Andersen, L.B.; Bull, F.C.; Guthold, R.; Haskell, W.; Ekelund, U.; Alkandari, J.R.; Bauman, A.E.; Blair, S.N.; Brownson, R.C.; et al. Global physical activity levels: Surveillance progress, pitfalls, and prospects. Lancet 2012, 380, 247-257. [CrossRef]

44. Hotamisligil, G.S.; Peraldi, P.; Budavari, A.; Ellis, R.; White, M.F.; Spiegelman, B.M. IRS-1-mediated inhibition of insulin receptor tyrosine kinase activity in TNF-alpha and obesity-induced insulin resistance. Science 1996, 271, 665-668. [CrossRef] [PubMed]

45. Gao, Z.; Hwang, D.; Bataille, F.; Lefevre, M.; York, D.; Quon, M.J.; Ye, J. Serine phosphorylation of insulin receptor substrate 1 by inhibitor kappa B kinase complex. J. Biol. Chem. 2002, 277, 48115-48121. [CrossRef] [PubMed]

46. Pavlov, V.A.; Tracey, K.J. Neural regulation of immunity: Molecular mechanisms and clinical translation. Nat. Neurosci. 2017, 20, 156-166. [CrossRef]

47. Obermeier, B.; Daneman, R.; Ransohoff, R.M. Development, maintenance and disruption of the blood-brain barrier. Nat. Med. 2013, 19, 1584-1596. [CrossRef]

48. Prinz, M.; Priller, J. The role of peripheral immune cells in the CNS in steady state and disease. Nat. Neurosci. 2017, 20, 136-144. [CrossRef]

49. Estrada, J.A.; Contreras, I. Nutritional Modulation of Immune and Central Nervous System Homeostasis: The Role of Diet in Development of Neuroinflammation and Neurological Disease. Nutrients 2019, 11, 1076. [CrossRef]

50. Das, M.; Mohapatra, S.; Mohapatra, S.S. New perspectives on central and peripheral immune responses to acute traumatic brain injury. J. Neuroinflamm. 2012, 9, 236. [CrossRef] 
51. McGrattan, A.M.; McGuinness, B.; McKinley, M.C.; Kee, F.; Passmore, P.; Woodside, J.V.; McEvoy, C.T. Diet and Inflammation in Cognitive Ageing and Alzheimer's Disease. Curr. Nutr. Rep. 2019, 8, 53-65. [CrossRef] [PubMed]

52. Báez-Mendoza, R.; Schultz, W. The role of the striatum in social behavior. Front. Neurosci. 2013, 7, 233. [CrossRef] [PubMed]

53. Hollerman, J.R.; Tremblay, L.; Schultz, W. Involvement of basal ganglia and orbitofrontal cortex in goal-directed behavior. Prog. Brain Res. 2000, 126, 193-215.

54. Seidl, S.E.; Santiago, J.A.; Bilyk, H.; Potashkin, J.A. The emerging role of nutrition in Parkinson's disease. Front. Aging Neurosci. 2014, 6, 36. [CrossRef] [PubMed]

55. Jackson, A.; Forsyth, C.B.; Shaikh, M.; Voigt, R.M.; Engen, P.A.; Ramirez, V.; Keshavarzian, A. Diet in Parkinson's Disease: Critical Role for the Microbiome. Front. Neurol. 2019, 10, 1245. [CrossRef]

56. Briguglio, M.; Dell'Osso, B.; Panzica, G.; Malgaroli, A.; Banfi, G.; Zanaboni Dina, C.; Galentino, R.; Porta, M. Dietary Neurotransmitters: A Narrative Review on Current Knowledge. Nutrients 2018, 10, 591. [CrossRef]

57. Marosi, K.; Kim, S.W.; Moehl, K.; Scheibye-Knudsen, M.; Cheng, A.; Cutler, R.; Camandola, S.; Mattson, M.P. 3-Hydroxybutyrate regulates energy metabolism and induces BDNF expression in cerebral cortical neurons. J. Neurochem. 2016, 139, 769-781. [CrossRef]

58. Ghisoni, K.; de PRDPMartins, R.; Barbeito, L.; Latini, A. Neopterin as a Potential Cytoprotective Brain Molecule. J. Psych. Res. 2015, 71, 134-139. [CrossRef]

59. Widner, B.; Leblhuber, F.; Fuchs, D. Increased neopterin production and tryptophan degradation in advanced Parkinson's disease. J. Neural Transm. 2002, 109, 181-189. [CrossRef]

60. Biswas, P.; Dellanoce, C.; Vezzoli, A.; Mrakic-Sposta, S.; Malnati, M.; Beretta, A.; Accinni, R. Antioxidant Activity with Increased Endogenous Levels of Vitamin C, E and A Following Dietary Supplementation with a Combination of Glutathione and Resveratrol Precursors. Nutrients 2002, 12, 3224. [CrossRef]

61. Vasconcelos, A.R.; Dos Santos, N.B.; Scavone, C.; Munhoz, C.D. Nrf2/ARE Pathway Modulation by Dietary Energy Regulation in Neurological Disorders. Front. Pharmacol. 2019, 10, 33. [CrossRef] [PubMed]

62. Kuehne, L.K.; Reiber, H.; Bechter, K.; Hagberg, L.; Fuchs, D. Cerebrospinal fluid neopterin is brain-derived and not associated with blood-CSF barrier dysfunction in non-inflammatory affective and schizophrenic spectrum disorders. J. Psychiatr. Res. 2013, 47, 1417-1422. [CrossRef] [PubMed]

63. De Paula Martins, R.; Ghisoni, K.; Lim, C.K.; Aguiar, A.S., Jr.; Guillemin, G.J.; Latini, A. Neopterin preconditioning prevents inflammasome activation in mammalian astrocytes. Free Radic. Biol. Med. 2018, 115, 371-382. [CrossRef] [PubMed]

64. Yu, J.; Zhu, H.; Gattoni-Celli, S.; Taheri, S.; Kindy, M.S. Dietary supplementation of GrandFusion ${ }^{\circledR}$ mitigates cerebral ischemiainduced neuronal damage and attenuates inflammation. Nutr. Neurosci. 2016, 19, 290-300. [CrossRef] [PubMed] 